\section{The Associations Between Internalized Racism, Racial Identity, and Psychological Distress}

\author{
Henry A. Willis' $\odot$, Effua E. Sosoo', Donte L. Bernard², \\ Aaron $\mathrm{Neal}^{3}$, and Enrique W. Neblett ${ }^{3}$
}

Emerging Adulthood

202I, Vol. 9(4) 384-400

(C) 202I Society for the

Study of Emerging Adulthood

and SAGE Publishing

(c) (i)

Article reuse guidelines:

sagepub.com/journals-permissions DOI: I0.II77/2।6769682|I005598 journals.sagepub.com/home/eax

(S)SAGE

\begin{abstract}
Internalized racism, or the acceptance of negative stereotypes about one's own racial group, is associated with psychological distress; yet, few studies have explored the longitudinal impact of internalized racism on the psychological well-being of African American emerging adults. Furthermore, racial identity's role as a protective factor in the context of internalized racism remains unclear. This study examined the longitudinal impact of internalized racism on psychological distress (depressive and anxiety symptoms) and the moderating role of racial identity beliefs among I7I African American emerging adults. Full cross-lagged panel models revealed no main effects of internalized racism beliefs on psychological distress. However, several racial identity beliefs moderated the relationship between internalized racism beliefs and changes in psychological distress over a year later. Initial levels of alteration of physical appearance, internalization of negative stereotypes, and hair change internalized racism beliefs were related to subsequent psychological distress, but only for those with certain levels of racial centrality, private regard, public regard, and assimilationist, humanist, and nationalist ideology beliefs. These findings suggest that, over time, internalized racism and racial identity beliefs can combine to influence the psychological well-being of African American emerging adults.
\end{abstract}

\title{
Keywords
}

internalized racism, racial identity, psychological distress, African Americans

Internalized racism, or the acceptance of negative stereotypes about one's own racial group, has been associated with psychological distress among African Americans (e.g., Molina \& James, 2016; Mouzon \& McLean, 2017; Sosoo et al., 2019); yet, not all individuals who endorse internalized racism beliefs evidence negative outcomes. Racial identity, a well-known protective factor against the negative mental health effects of racism-related stress (Neblett et al., 2012), may protect against the negative effects of internalized racism, but empirical support is limited. To address this gap, this study explored the longitudinal impact of internalized racism dimensions on psychological distress associated with depressive and anxiety symptoms and the moderating role of racial identity in a sample of African American emerging adults.

\section{Internalized Racism}

Jones (2000) described three different levels of racism: personally-mediated (e.g., racial discrimination); institutionalized (i.e., inequitable access to products, services, and opportunities based on race); and internalized (i.e., acceptance of negative stereotypes or beliefs by the stigmatized group about their own race). Internalized racism is conceptualized as the product of systems of privilege and societal values that, over time, erode an individual's sense of value and undermine the collective action of a minority racial and/or ethnic group (Jones, 2000). Scholars argue that internalized racism represents a multidimensional construct, distinct from racial discrimination (e.g., Bailey et al., 2011; David et al., 2019), that includes: belief in a biased representation of history (acceptance of distorted historical facts that favor the White majority; Clarke, 1991), internalization of negative stereotypes (accepting the negative stereotypes about African Americans; Cokley, 2002), and

\footnotetext{
'University of North Carolina at Chapel Hill, NC, USA

${ }^{2}$ Medical University of South Carolina, SC, USA

${ }^{3}$ University of Michigan, MI, USA
}

\section{Corresponding Author:}

Henry A. Willis, MA, Department of Psychology and Neuroscience, University of North Carolina at Chapel Hill, Chapel Hill, NC, USA.

Email: henry.willis@unc.edu 
alteration of physical appearance (an individual's conscious or unconscious desire or attempts to change their appearance to fit a Eurocentric aesthetic including perceptions of hair; Parmer et al., 2004).

Clark and colleagues' (1999) biopsychosocial model of racism posits that racism results in psychological and physiological stress responses that can be linked to negative psychological wellbeing, and Jones' (2000) model categorizes internalized racism as a stressor for African Americans. While recent empirical research has documented the impact of racial discrimination on the psychological outcomes of African Americans (e.g., Priest et al., 2013), and attention to internalized racism has increased in the past decade (David et al., 2019), the unique impact of the other levels of racism as put forth by Jones (2000), and how internalized racism may interact with other race-related phenomena, such as racial identity beliefs, remains unclear.

\section{Developmental Significance and Context}

During the developmental period of emerging adulthood, African American young adults, particularly those attending predominantly White universities, may be at increased risk of experiencing race-related stress (Hurd et al., 2014; Smedley et al., 1993). Many areas of the educational system in the United States promote a Eurocentric pedagogical tradition, which serves to alienate students of African descent from the curriculum, consequently perpetuating internalized racism (Perry et al., 2003). These negative experiences also occur at a time when there is reduced parental involvement and support relative to childhood and adolescence (Arnett, 2003). Additionally, the developmental task of developing a healthy identity may be an area of increased stress for this population as they grapple with the significance and meaning of an identity that is commonly devalued in society (Graham et al., 2013; Sue, 2010) and is often in direct conflict with the Eurocentric values of independence, autonomy, and self-sufficiency (Arnett, 2003). Others have suggested that the difficulties African American young adults face during this developmental period may account, in part, for the increased prevalence of depression and anxiety disorders (Babajide et al., 2020) and increased vulnerability to substance use (Doherty et al., 2008; Gil et al., 2002) and suicide risk (Castle et al., 2011). Together, the challenges that African American young adults face, combined with the developmental tasks of emerging adulthood, highlight the need to explore African American emerging adults' experiences of internalized racism.

\section{Internalized Racism and Psychological Distress}

In light of evidence linking internalized racism with physical and psychosocial factors associated with psychological wellbeing (e.g., obesity, perceived stress, sleep problems; FullerRowell et al., 2020; Tull et al., 1999), it is not surprising that prior research (e.g., Taylor et al., 1991) supports a link between internalized racism and psychological distress for African Americans. Williams and Chung (1999) found that African Americans who endorsed negative stereotypes about African Americans had higher levels of psychological distress, and that the rejection of positive stereotypes was inversely related to life satisfaction and happiness. More recently, Mouzon and Mclean (2017) reported that internalized racism was positively associated with both depressive symptoms and serious psychological distress (which included symptoms of anxiety) in a large African American sample. Graham et al. (2016) found that internalized racism mediated the relationship between past racist experiences and anxiety symptoms, and a recent study examining hair change attitudes found that these attitudes (e.g., "straight hair is better than my natural hair texture") exacerbated the association between racial discrimination and subsequent anxiety symptom distress (Sosoo et al., 2019). Taken together, empirical investigations support the notion that internalized racism dimensions may have direct and indirect effects on African American mental health.

\section{The Protective Role of Racial Identity}

Not all African Americans who experience racism-related stress are vulnerable to its negative effects. Racial identity, which can be defined as the significance and meaning that race has in the self-concepts of African Americans (Sellers et al., 1997), may be a protective factor against forms of racerelated stress such as racial discrimination. For example, several studies have illustrated that racial identity is associated with positive well-being and better mental health outcomes within African American samples, and that it buffers against the negative effects of racial discrimination (e.g., Banks \& Kohn-Wood, 2007; Seaton, 2009). One way racial identity may protect against the effects of internalized racism is by enhancing self-concept, self-esteem, and cognitive-appraisal processes, as well as facilitating the development of adaptive coping styles (Neblett et al., 2012).

\section{Conceptualizing Racial Identity}

The Multidimensional Model of Racial Identity (MMRI; Sellers et al., 1997) is one framework that can elucidate how racial identity may protect against the effects of internalized racism on psychological distress. The MMRI consists of four dimensions that refer to the significance and qualitative meaning race has in African Americans' self-concepts: salience, centrality, regard, and ideology. Salience (not examined in this study) measures the extent to which individuals' races are relevant to their self-concept during a specific moment, whereas centrality corresponds to the extent to which individuals define themselves according to their race over time and across situations (Sellers et al., 1997). Both salience and centrality measure the significance individuals attach to race with regard to defining themselves.

Additionally, regard, which measures the extent to which individuals feel positively about their race, and ideology, which 
measures individuals' beliefs, attitudes, or opinions about how they feel people from their race should act, reflect the perceptions one has about the meaning of being Black or African American (Sellers et al., 1997). Racial regard consists of two sub-dimensions: public regard and private regard. Public regard refers to the extent to which individuals feel that others view African Americans positively or negatively. Private regard measures the extent to which individuals feel positively or negatively about being African American and about other African Americans. Finally, Sellers et al. (1997) describe ideology as consisting of four sub-dimensions: (1) assimilationist (which stresses the similarities between African Americans and American society); (2) humanist (which refers to the view that all humans, regardless of racial/ethnic background, are similar); (3) oppressed minority (which emphasizes the commonalities between the oppression that African Americans face with that of other groups); and (4) nationalist (characterized by views that the African American experience is unique).

Several dimensions of racial identity as measured by the MMRI have been useful when investigating the protective role of racial identity (e.g. Banks \& Kohn-Wood, 2007; Neblett \& Carter, 2012; Seaton, 2009). For example, Sellers and colleagues (2006) found that African American adolescents with low public regard were at the greatest risk of experiencing racial discrimination, but protected against the impact of racial discrimination on psychological functioning. Furthermore, private regard has been shown to buffer the effects of racial discrimination on mental health symptoms (Bynum et al., 2008). Similarly, it has been shown that African American emerging adults with high levels of racial centrality and low public regard report lower depressive symptoms and appear to be protected against the effects of perceived racism (Seaton, 2009). In contrast, it has been shown that low private regard, low racial centrality, and high assimilationist and humanist ideologies exacerbate the relationship between racial discrimination and depressive symptoms, highlighting that some levels and dimensions of racial identity may not be protective in every context (Banks \& Kohn-Wood, 2007; Seaton, 2009). Although many findings support the role of racial identity as a protective factor against racial discrimination, there is a dearth of information on how this construct may protect against internalized racism.

\section{Limitations of Prior Research}

Despite prior research linking racism-related stress to psychological distress and promising findings regarding the protective function of racial identity in the context of racial discrimination, current literature has not adequately explored the unique impact of internalized racism above and beyond experiences of racial discrimination. Previous studies have looked at internalized racism as a moderator or mediator between racial discrimination and psychological distress (i.e., Graham et al., 2016; Molina \& James, 2016; Sosoo et al., 2019) instead of examining the direct effects of internalized racism on psychological well-being. Although racial discrimination may contribute to the internalization of negative stereotypes or intensify the deleterious effects of other internalized racism attitudes and beliefs, researchers have also postulated that the awareness and internalization of negative stereotypes may produce psychologically threatening situations in the absence of experiences of racial discrimination, and that internalized racism could be the most damaging form of racism (Speight, 2007).

Second, researchers have not determined the moderating role of racial identity on the relationship between internalized racism and psychological distress. Although there is support for the protective role of racial identity in the relationship between interpersonal experiences of race-related stress and depressive symptoms (i.e., Smith \& Silva, 2011), it is not known if racial identity is protective in the relationship between internalized racism and psychological well-being. Racial identity might be protective for African Americans in that it may equip them with alternative, adaptive beliefs that counteract internalized racism beliefs. Furthermore, as highlighted by Bailey and colleagues (2011), many past empirical investigations of internalized racism have focused on the internalization of negative stereotypes or self-hatred attitudes. Thus, there is a need for studies to explore how other dimensions of internalized racism, such as desires to adopt Western/Eurocentric standards of beauty (i.e., alteration of physical appearance) or minimizing one's racial-ethnic history (i.e., belief in a biased representation of history), impact psychological distress.

Finally, past studies exploring internalized racism have used cross-sectional designs (e.g., Mouzon \& McLean, 2017), which limits our understanding of how internalized racism may impact and influence changes in psychological distress. Going forward, studies should utilize a longitudinal design to elucidate how internalized racism may impact psychological wellbeing over time and to determine if racial identity protects against the effects of internalized racism on the development of subsequent psychological distress.

\section{Current Study}

This study examined the longitudinal associations between internalized racism, racial identity, and psychological distress among African American young students at a predominately White institution. We were specifically interested in distress associated with depression and anxiety given the relatively higher rates of these symptoms during the transition to adulthood. Consistent with past research exploring the impact of internalized racism (Carter, 2007; Mouzon \& McLean, 2017; Speight, 2007; Taylor, 1990; Taylor et al., 1991; Williams \& Chung, 1999), it was expected that initial levels of internalized racism dimensions (e.g., internalization of negative stereotypes, belief in a biased representation of history, alteration of physical appearance, and hair change attitudes; Bailey et al., 2011) would be significantly associated with subsequent distress from depressive and anxiety symptoms, adjusting for initial levels of psychological distress and racial discrimination experiences. Second, it was expected that certain racial identity beliefs would moderate the association between internalized racism and psychological distress (Banks \& Kohn-Wood, 
2007; Bernard et al, 2018). Consistent with Seaton (2009), high levels of racial centrality and private regard, and low public regard, were expected to buffer against the adverse impact of internalized racism. It could be that these racial identity dimensions equip African American emerging adults with more positive attitudes about their race and higher self-esteem, which in turn aids them in managing negative beliefs about themselves and/or their racial-ethnic group as a result of internalized racism.

\section{Method}

\section{Participants}

Participants were 171 (69\% female) African American young adults from a multi-wave longitudinal research project examining the health and life experiences of African American students. Data were collected in two successive cohorts beginning in 2013, and there was a semester-interval of approximately 8 months between waves. The current study focused on the first (W1) and third waves (W3) of the study. Participants were required to be at least 18 years of age and selfidentify as African American. At Wave 1 (W1), participants were an average age of $18.3(S D=.47$; range $=18-20)$.

The median highest maternal educational attainment was "Bachelors or 4-year college degree." Self-reported family socioeconomic status was reported as: $7 \%$ poor, $19.3 \%$ working class, $50.9 \%$ middle class, $22.2 \%$ upper middle class, and $.6 \%$ wealthy. $28.7 \%(n=49)$ of our sample self-identified as first-generation college students, and $29.8 \%(n=51)$ reported being from a single-parent home.

\section{Measures}

Internalized racism. Internalized racism experiences were assessed at both waves using the Internalized Racial Oppression Scale (IROS; Bailey et al., 2011). The IROS is a 28item self-report measure that asks participants to rate their agreement with several statements using a 5-point Likert-type rating scale from $1=$ strongly disagree to $5=$ strongly agree. Sample items from this scale correspond to several aspects of internalized racism: internalization of negative stereotypes (e.g., "Most Black people are on welfare"; W1: $\alpha=.86$; W3: $\alpha=.82$ ), belief in a biased representation of history (e.g., "Cannabalism was widely practiced in Africa"; W1: $\alpha=.61$; W3: $\alpha=.69$ ), altering physical appearance (e.g., "It is fine to use skin care products to lighten skin color"; W1: $\alpha=.83$; W3: $\alpha=.83$ ), and hair change (e.g., "Straight hair is better than my natural hair texture"; W1: $\alpha=.67$; W3: $\alpha=.67$ ). Bailey and colleagues (2011) have illustrated evidence of criterion-related validity of the IROS, and reliability estimates in previous studies have ranged from .68 to .90 for the total scale and its subscales (Bailey et al., 2011; Brown \& Segrist, 2015; Sosoo et al., 2019).

Racial identity. Racial identity was assessed at both waves using the short form of the Multidimensional Inventory of Black
Identity (MIBI-S; Martin et al., 2010). The MIBI-S is a selfreport measure used to assess the three stable dimensions of racial identity: centrality, regard, and ideology. The MIBI-S is a shortened version of the original MIBI and was developed using confirmatory factor analysis. This version of the MIBI has been shown to be more reliable and provided a better fit than the original MIBI (Martin et al., 2010). Participants were asked to respond to each of the items using a 7-point Likerttype rating scale from $1=$ strongly disagree to $7=$ strongly agree. Racial centrality assessed the extent to which individuals believe race is a central aspect of their identity (e.g., "I have a strong sense of belonging to Black people; 4 items; W1: $\alpha=.70 ; \mathrm{W} 3: \alpha=.70$ ). Racial regard assessed the degree to which an individual feels positively toward their racial group (e.g., "I feel good about Black people"; private regard; 3 items; W1: $\alpha=.85$; W3: $\alpha=.86$ ) and how an individual believes others view Blacks (e.g., "Overall, Blacks are considered good by others"; public regard; 4 items; W1: $\alpha=.85$; W3: $\alpha=.80$ ). Ideology, or an individual's beliefs regarding how people from their race should act, was measured using four sub-dimensions: assimilationist ideology (e.g., "Blacks should strive to integrate all institutions which are segregated"; 4 items; W1: $\alpha=.72 ; \mathrm{W} 3: \alpha=.73)$, humanist ideology (e.g., "Being an individual is more important than identifying oneself as Black"; 4 items; W1: $\alpha=.62$; W3: $\alpha=.67$; oppressed minority ideology (e.g., "There are other people who experience racial injustice and indignities similar to Black Americans"; 4 items; W1: $\alpha=.73 ; \mathrm{W} 3: \alpha=.70$ ) and nationalist ideology (e.g., "Blacks would be better off if they adopted Afrocentric values"; 4 items; W1: $\alpha=.58$; W3: $\alpha=.76$ ). Previous research has provided evidence of construct and predictive validity for the MIBI in large African American college samples (e.g., Banks \& Kohn-Wood, 2007; Sellers et al., 1997; Willis \& Neblett, 2019), with reliability analyses in previous studies producing Cronbach's alphas that range from .61 to .81 .

Racial discrimination. Racial discrimination during the past year was assessed at both waves using the Daily Life Experiences Scale (DLE; Harrell, 1994). The DLE is a 28 -item subscale of Harrell's (1994) Racism and Life Experiences scale, which is used to assess past experiences of discrimination. The DLE assesses the frequency and distress associated with 18 race-related microaggressions. The frequency of each microaggression was rated from $0=$ never to $5=$ once a week or more (W1: $\alpha=.92 ; \mathrm{W} 3: \alpha=.94$ ). The distress associated with each microaggression was rated from $0=$ has never happened to me to $5=$ bothers me extremely (W1: $\alpha=.97$; W3: $\alpha=.93$ ). Scores were averaged to create mean scores, and higher scores corresponded to more frequent experiences and greater distress associated with racial discrimination. Prior research demonstrates strong evidence for the psychometric properties of the DLE (Lee et al., in press).

Psychological distress. Depressive and anxiety symptom distress were assessed at both waves using the Symptom Checklist 
90-Revised (SCL-90-R; Derogatis, 1996; Derogatis \& Unger, 2010). The SCL-90-R is a 90 -item self-report measure used to assess psychological distress. This measure consists of 9 subscales; however, the present study focused on the depression (e.g., crying easily, feeling lonely; W1: $\alpha=.88$; W3: $\alpha=.87$ ) and anxiety subscales (W1: $\alpha=.79$; W3: $\alpha=.79$ ). The extent to which each item had distressed participants during the past 7 days was rated from $0=$ not at all to $4=$ extremely. Higher scores reflect higher levels of psychiatric conditions. Previous research demonstrates strong evidence for the reliability and validity of this measure (Horowitz et al., 1988; Peveler \& Fairburn, 1990).

\section{Procedure}

Following university Institutional Review Board approval, participants were recruited utilizing a list of incoming African American students provided by the registrar's office. Eligible participants completed a battery of online and paper and pencil questionnaires in survey administrations lasting approximately $1 \mathrm{hr}$. Participants completed the same battery of questionnaires during the third wave of data collection, and participants received a payment of $\$ 15$ at each wave of data collection.

\section{Results}

\section{Preliminary Analyses and Analytic Plan}

Descriptive statistics and bivariate correlations for demographic and key study variables are reported in Table 1. W1 Biased Representation of History was positively correlated with W3 anxiety distress. W1 Alteration of Physical Appearance and Internalization of Negative Stereotypes, but not Hair Change, were positively correlated with W3 depression and anxiety distress.

Next, we examined the associations between internalized racism, racial identity and psychological distress (i.e., depression, anxiety) using a full cross-lagged panel design. We ran four models examining each of the internalized racism subscales independently. In addition to the simultaneous inclusion of all seven dimensions of racial identity at both waves in each model, all two-way internalized racism $\mathrm{x}$ racial identity interactions were modeled (again simultaneously) as covariates to test the effects of internalized racism and racial identity at W1 and their interaction on subsequent psychological distress at W3 (controlling for initial levels of distress). Preliminary models also included age, maternal educational attainment, gender, cohort, and prior racial discrimination frequency and distress as covariates; however, after determining that the results remained the same, nonsignificant covariates were removed from the final reported models to optimize model fits and parsimony. We used full information maximum likelihood estimation with missing data in Mplus v. 8.4. Chi-square, comparative fit index (CFI), Tucker-Lewis index (TLI), and root-mean-square error of approximation (RMSEA) goodness-of-fit indices are reported for each model. Continuous predictor variables were centered to reduce multicollinearity between the main effects and interactions. Significant interactions between internalized racism (at $-1 \mathrm{SD}$, mean, $+1 \mathrm{SD}$ ) and racial identity (from -1 to $+1 \mathrm{SD}$ ) were probed and interpreted using Loop Plots in MPlus, and we tested the simple slopes of the regression lines.

\section{Internalized Racism, Racial Identity, and Psychological Distress}

Standardized and unstandardized coefficients (along with standard errors and $p$ values) for longitudinal paths predicting W3 psychological distress are presented for each internalized racism subscale in Table 2 (depression) and Table 3 (anxiety). These results are reported separately for the sake of clarity; however, the results for depression and anxiety for each internalized racism subscale originate from the same "parent" internalized racism model (e.g., the depression and anxiety coefficients for biased representation of history originate from the biased representation of history model). Figures 1A-1D depict the significant pathways involving each internalized racism scale, relevant racial identity dimensions, and psychological distress at $\mathrm{W} 1$ and $\mathrm{W} 3$. These figures demonstrate that all dimensions of internalized racism, racial identity, and depression and anxiety distress exerted positive auto-regressive effects suggesting a high degree of consistency in these constructs over time. Also, study covariates were associated with W3 endogenous variables, racial identity dimensions at W1 predicted racial identity dimensions at $\mathrm{W} 3$, psychological distress at $\mathrm{W} 1$ predicted racial identity at $\mathrm{W} 3$, and $\mathrm{W} 1$ private regard negatively predicted W3 depression distress (see Supplemental Material at https://osf.io/32ebc/?view_o nly $=7 \mathrm{~b} 10 \mathrm{cc} 4392364304 \mathrm{a} 719144 \mathrm{cb} 437 \mathrm{aabbfordetailedre}$ sults).

Biased representation of history. The fit indices for the model examining belief in a biased representation of history and psychological distress suggested excellent fit to the data $\left(\mathrm{CFI}=1.00, \mathrm{TLI}=1.00, \mathrm{RSMEA}=.00[.00, .03], \chi^{2}(88)=\right.$ $75.51, p=.83$ ). Maternal educational attainment (W1) was negatively associated with biased representation of history beliefs at W3. Racial identity at W1 predicted W3 biased representation of history beliefs. Specifically, W1 public regard beliefs were positively associated with biased representation of history beliefs at $\mathrm{W} 3$, while nationalist ideology at W1 was negatively associated with $\mathrm{W} 3$ biased representation of history beliefs (Figure 1A).

Depression. After controlling for study covariates, belief in a biased representation of history at $\mathrm{W} 1$ did not predict greater depression distress at $\mathrm{W} 3(\beta=-0.08, S E=0.10, p=.30)$, and none of the biased representation of history $\mathrm{x}$ racial identity interactions was statistically significant.

Anxiety. W1 biased representation of history was unrelated to W3 anxiety distress $(\beta=-0.00, S E=0.07, p=.99)$. None of the biased representation of history $\mathrm{x}$ racial identity interactions was statistically significant. 


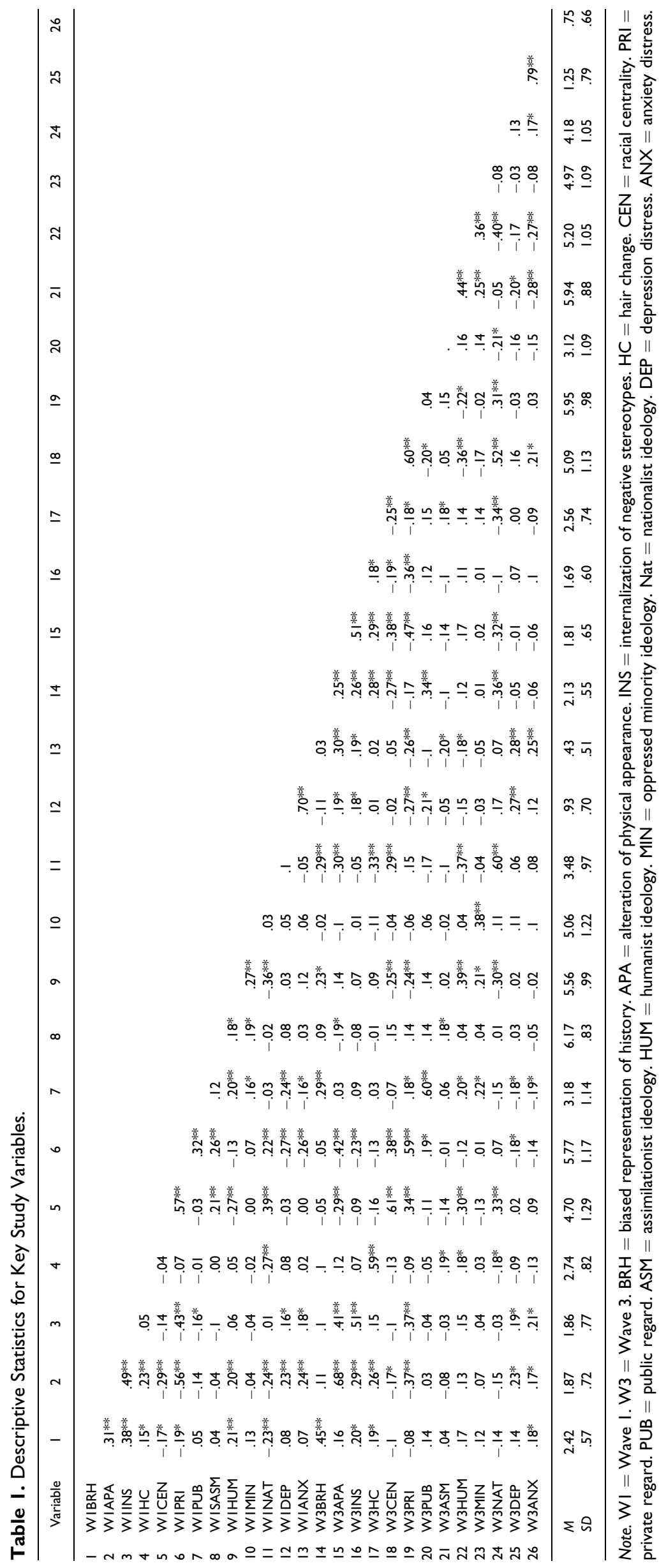


Table 2. Standardized and Unstandardized Coefficients for the Cross-Lagged Effects of TI Internalized Racism, Racial Identity, and Covariates Predicting W3 Depression Distress.

\begin{tabular}{|c|c|c|c|c|c|c|}
\hline Predictor & & $\beta$ & & $b$ & $S E$ & $P$ \\
\hline Cohort & - & 0.66 & - & 1.04 & 0.10 & .00 \\
\hline Biased Representation of History & - & 0.08 & - & 0.11 & 0.10 & .30 \\
\hline WI Centrality & & 0.12 & & 0.07 & 0.06 & .19 \\
\hline WI Private Regard & - & 0.14 & - & 0.09 & 0.06 & .14 \\
\hline WI Humanist Ideology & - & 0.00 & - & 0.00 & 0.06 & .96 \\
\hline WI Oppressed Minority Ideology & & 0.04 & & 0.03 & 0.04 & .53 \\
\hline WI Nationalist Ideology & - & 0.02 & - & 0.02 & 0.06 & .79 \\
\hline WI Depression & & 0.22 & & 0.24 & 0.10 & .02 \\
\hline WI Anxiety & & 0.15 & & 0.23 & 0.13 & .08 \\
\hline Centrality $\times$ BRH & - & 0.10 & - & 0.11 & 0.10 & .30 \\
\hline Oppressed Minority $\times$ BRH & & 0.11 & & 0.11 & 0.09 & .19 \\
\hline Nationalist $\times$ BRH & & 0.04 & & 0.05 & 0.10 & .60 \\
\hline \multicolumn{7}{|l|}{ Alteration of Physical Appearance (APA) } \\
\hline Cohort & - & 0.66 & - & 1.04 & 0.11 & .00 \\
\hline Gender & - & 0.10 & - & 0.18 & 0.11 & .12 \\
\hline Alteration of Physical Appearance & - & 0.03 & - & 0.03 & 0.09 & .70 \\
\hline WI Centrality & & 0.07 & & 0.04 & 0.06 & .44 \\
\hline WI Private Regard & - & 0.09 & - & 0.06 & 0.07 & .41 \\
\hline WI Public Regard & - & 0.04 & - & 0.02 & 0.05 & .62 \\
\hline WI Assimilationist Ideology & - & 0.03 & - & 0.02 & 0.06 & .70 \\
\hline WI Humanist Ideology & & 0.00 & & 0.00 & 0.06 & .95 \\
\hline Assimilationist $\times$ APA & & 0.01 & & 0.01 & 0.09 & .91 \\
\hline Humanist $\times$ APA & - & 0.03 & - & 0.03 & 0.09 & .71 \\
\hline Oppressed Minority $\times$ APA & - & 0.02 & - & 0.02 & 0.06 & .75 \\
\hline Nationalist $\times$ APA & - & 0.07 & - & 0.07 & 0.08 & .38 \\
\hline \multicolumn{7}{|l|}{ Internalization of Negative Stereotypes } \\
\hline Cohort & - & 0.63 & - & 1.00 & 0.10 & .00 \\
\hline Gender & - & 0.18 & - & 0.30 & 0.12 & .01 \\
\hline Internalization of Negative Stereotypes & & 0.09 & & 0.09 & 0.08 & .26 \\
\hline WI Centrality & & 0.09 & & 0.06 & 0.05 & .28 \\
\hline WI Private Regard & - & 0.11 & - & 0.07 & 0.06 & .25 \\
\hline WI Public Regard & - & 0.01 & - & 0.01 & 0.05 & .91 \\
\hline WI Assimilationist Ideology & & 0.02 & & 0.02 & 0.06 & .76 \\
\hline WI Humanist Ideology & - & 0.01 & - & 0.01 & 0.06 & .92 \\
\hline WI Oppressed Minority Ideology & & 0.06 & & 0.04 & 0.04 & .37 \\
\hline WI Nationalist Ideology & & 0.00 & & 0.00 & 0.06 & .98 \\
\hline WI Depression & & 0.19 & & 0.21 & 0.10 & .04 \\
\hline WI Anxiety & & 0.18 & & 0.27 & 0.14 & .05 \\
\hline Centrality $\times$ INS & & 0.07 & & 0.06 & 0.07 & .45 \\
\hline Private Regard $\times$ INS & & 0.05 & & 0.03 & 0.07 & .62 \\
\hline Public Regard $\times$ INS & & 0.04 & & 0.03 & 0.06 & .64 \\
\hline
\end{tabular}


Table 2. (continued)

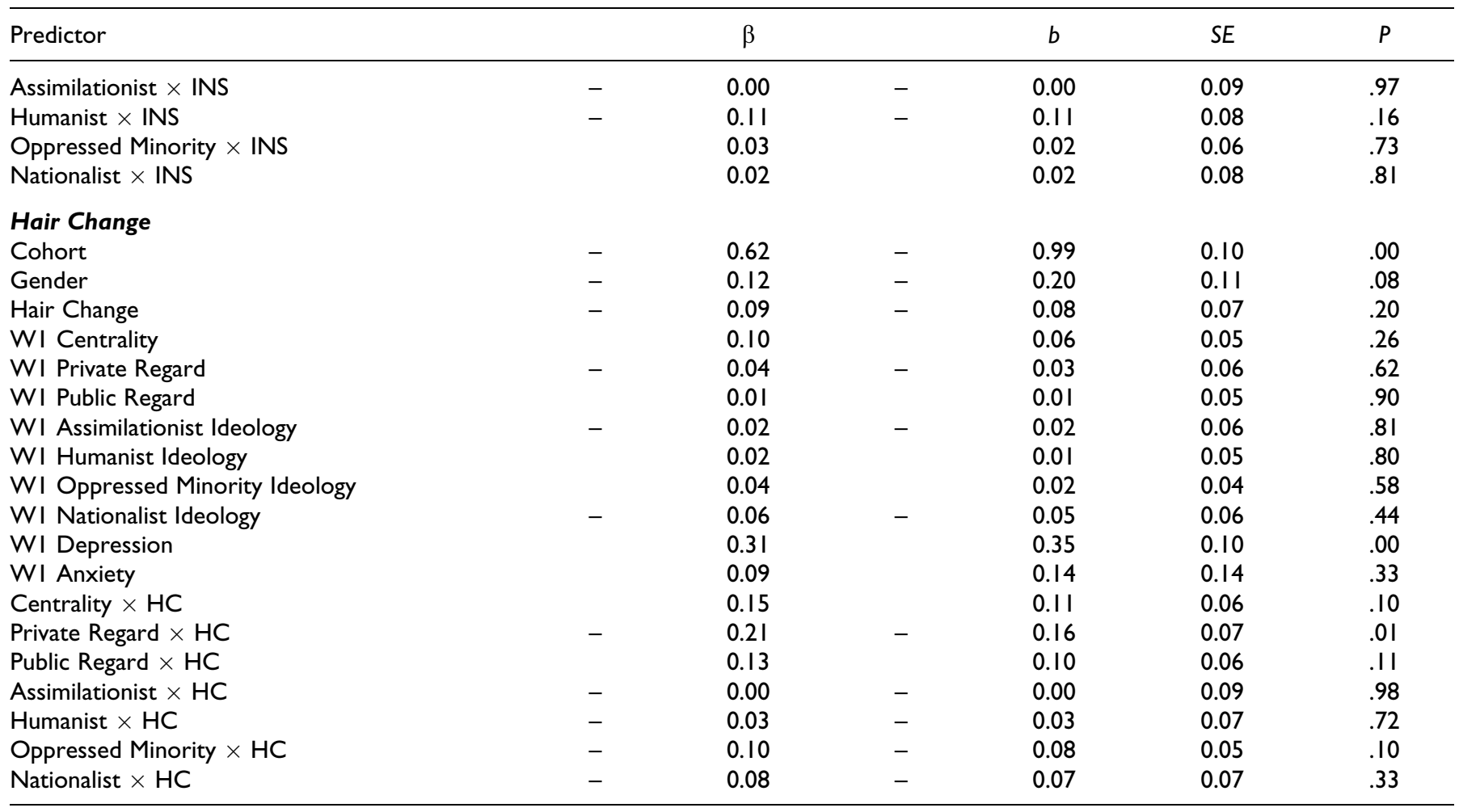

Note. Gender codling: $(0=$ female; I = male). Cohort coding: $(0=$ Cohort $2 ; \mathrm{I}=$ Cohort I $)$. WI = Wave I; W3 =Wave 3; BRH = biased representation of history; APA = alteration of physical appearance; INS = internalization of negative stereotypes; HC = hair change.

Alteration of physical appearance. The fit indices for the model examining alteration of physical appearance attitudes and psychological distress (Figure 1B) suggested excellent fit to the data $\left(\mathrm{CFI}=.99, \mathrm{TLI}=.97, \mathrm{RSMEA}=.03[.00, .05], \chi^{2}(87)=95.98\right.$, $p=.24)$. Cohort was associated with alteration of physical appearance attitudes at W3, such that participants in the first cohort were more likely to endorse alteration of physical appearance beliefs at W3. Women and participants with more prior discrimination experiences at $\mathrm{W} 1$ reported decreased alteration of physical appearance beliefs at W3. W1 alteration of physical appearance beliefs were unassociated with racial identity at W3. However, W1 assimilationist ideology was negatively associated with endorsement of alteration of physical appearance beliefs at $\mathrm{W} 3(\beta=-.17, p=.003)$, and $\mathrm{W} 1$ anxiety distress was positively associated with endorsement of W3 alteration of physical appearance beliefs $(\beta=.19, p=.02)$.

Depression. After controlling for study covariates, alteration of physical appearance at W1 did not predict greater depression distress at W3 $(\beta=-0.03, S E=0.09, p=.70)$, and none of the alteration of physical appearance $\mathrm{x}$ racial identity interactions was significant for depressive symptom distress.

Anxiety. Similar to depression distress, alteration of physical appearance beliefs at $\mathrm{W} 1 \mathrm{did}$ not predict greater anxiety distress at W3 $(\beta=-0.07, S E=0.06, p=.25)$. However, the interactions between alteration of physical appearance and private regard $(\beta=-0.20, S E=0.04, p=.01)$, and humanist ( $\beta=-0.13, S E=0.06, p=.04)$ ideology were significant. Simple slope analyses revealed that alteration of physical appearance beliefs were negatively associated with anxiety distress at high levels of private regard $(b=-.18, p=.02)$, but unrelated to anxiety distress at low $(b=.05, p=.50)$ and moderate $(b=$ $-.06, p=.25$ ) levels of private regard (Figure 2A). Alteration of physical appearance beliefs also were negatively associated with anxiety distress at high $(b=-.18, p=.03)$, but not low $(b=.05, p=.51)$ and moderate $(b=-.06, p=.25)$ levels of humanist ideology (Figure 2B). Individuals with the highest levels of private regard and humanist ideology had the lowest levels of anxiety distress even at high levels of biased representation of history endorsement. The two-way interactions predicting anxiety distress were not significant for alteration of physical appearance and the other racial identity dimensions.

Internalization of negative stereotypes. The fit indices for the model examining internalization of negative stereotypes and psychological distress (Figure 1C) suggested very good fit to the data $(\mathrm{CFI}=.98, \mathrm{TLI}=.94$, RSMEA $=.03[.00, .05]$, $\left.\chi^{2}(97)=113.33, p=.12\right)$. Women were more likely than men to have higher internalization of negative stereotypes beliefs at W3. Age (W1) was negatively correlated with W3 
Table 3. Standardized and Unstandardized Coefficients for the Cross-Lagged Effects of TI Internalized Racism, Racial Identity, and Covariates Predicting W3 Anxiety Distress.

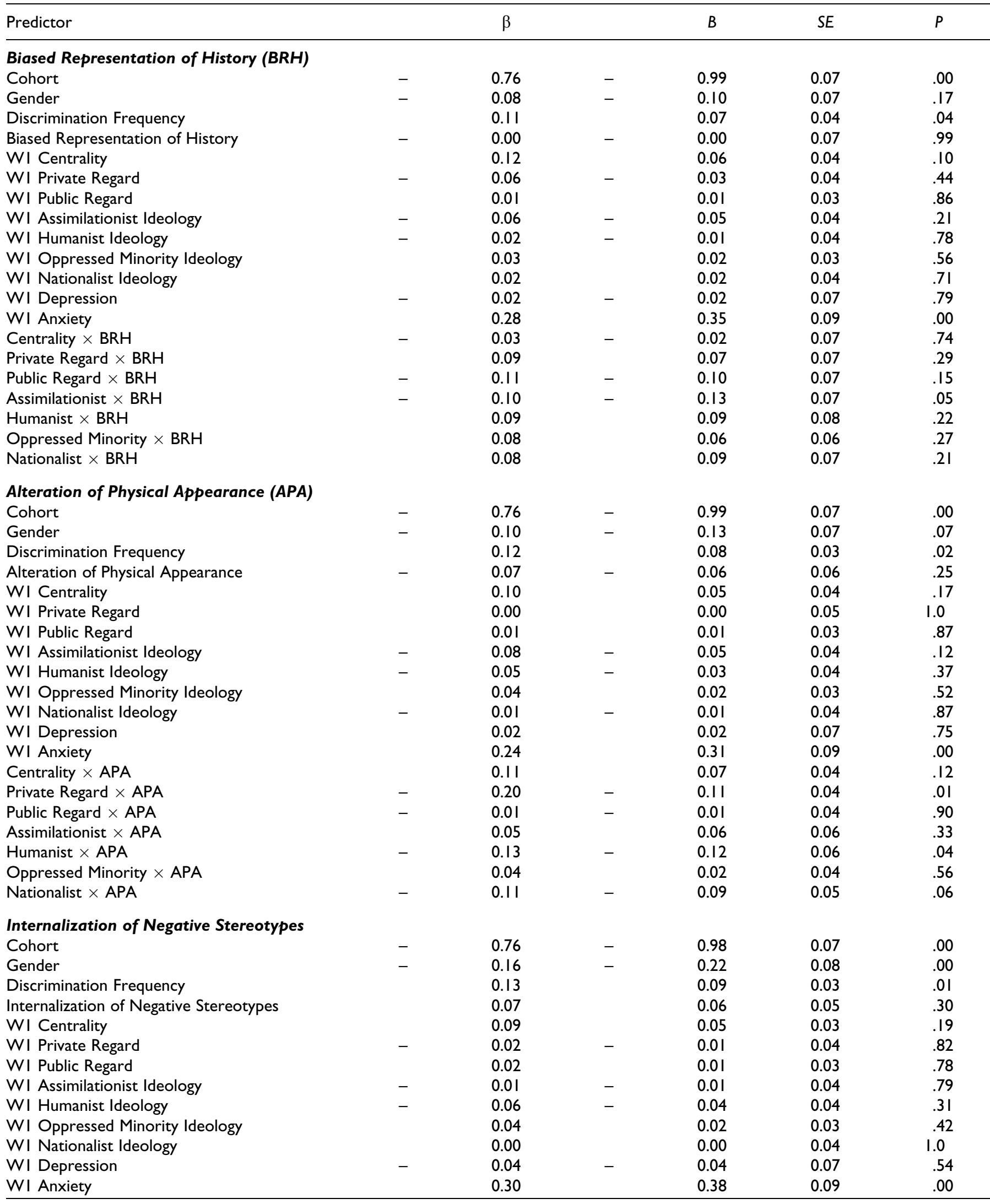


Table 3. (continued)

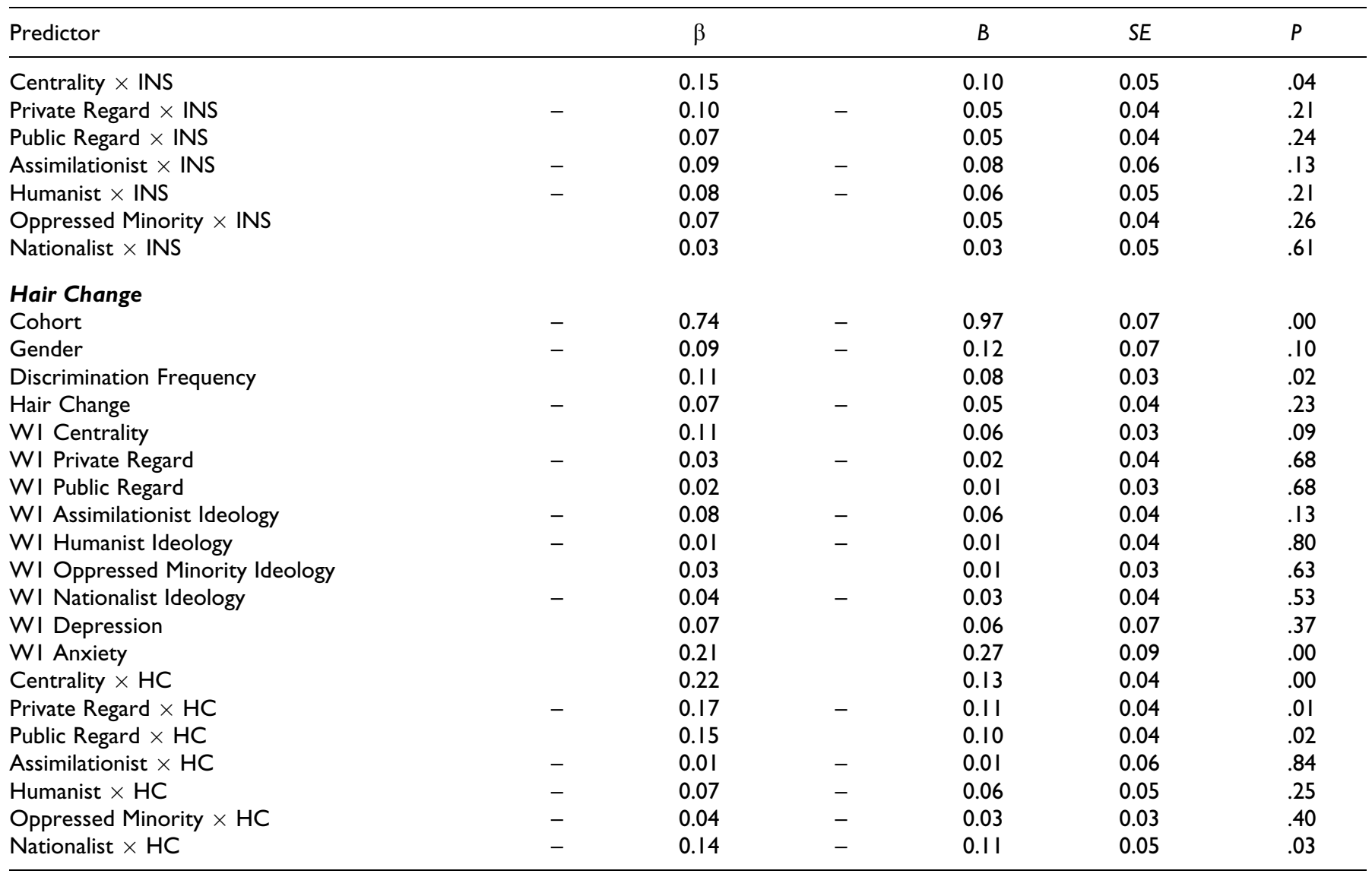

Note. Gender codling: $(0=$ female; I = male). Cohort coding: $(0=$ Cohort 2 ; I = Cohort I).WI = Wave I; W3 = Wave 3; BRH = biased representation of history; APA = alteration of physical appearance; INS = internalization of negative stereotypes; HC = hair change

internalization of negative stereotypes $(\beta=-.21, p=.005)$. Racial identity at W1 was unrelated to W3 internalization of negative stereotypes. W1 internalization of negative stereotypes beliefs were negatively associated with W3 private regard $(\beta=-.21, p=.004)$ and positively associated with W3 humanist ideology $(\beta=.20, p=.014)$.

Depression. After controlling for study covariates, internalization of negative stereotypes at W1 did not predict greater depression distress at $\mathrm{W} 3(\beta=0.09, S E=0.08, p=.26)$, and none of the internalization of negative stereotypes $\mathrm{x}$ racial identity interactions was significant.

Anxiety. After controlling for study covariates, internalization of negative stereotypes at $\mathrm{W} 1$ did not predict greater anxiety distress at W3 ( $\beta=0.07, S E=0.05, p=.30)$; however, the internalization of negative stereotypes $\mathrm{x}$ racial centrality interaction was statistically significant $(\beta=0.15, p=.04)$. Simple slope analyses revealed that internalization of negative stereotypes was positively associated with anxiety distress at high levels of racial centrality $(b=.15, p=.03)$, but unrelated to anxiety distress at low $(b=-.04, p=.53)$ and moderate $(b=.06, p=.30)$ levels of racial centrality (Figure 2C). Among individuals who endorsed the strongest internalization of negative stereotypes beliefs, those with the highest levels of racial centrality reported the highest levels of anxiety distress.

Hair change. The fit indices for the model examining hair change beliefs and psychological distress (Figure 1D) suggested excellent fit to the data (CFI $=1.00$, TLI $=1.00$, RSMEA $\left.=.00[.00, .04], \chi^{2}(99)=95.45, p=.58\right)$. Age at W1 was negatively associated with hair change beliefs at W3 $(b=-.16, p=.01)$. Racial identity at $\mathrm{W} 1$ was unrelated to W3 hair change beliefs.

Depression. After controlling for study covariates, hair change beliefs at $\mathrm{W} 1 \mathrm{did}$ not predict depression distress at W3 ( $\beta=-0.09, S E=0.07, p=.20)$. However, the hair change $\mathrm{x}$ private regard interaction was significant $(\beta=-0.21$, $S E=0.07, p=.01)$. Simple slope analyses revealed that hair change beliefs were negatively associated with depression distress at high levels of private regard $(b=-.25, p=.01)$, but unrelated to depression distress at low $(b=.08, p=.39)$ and 


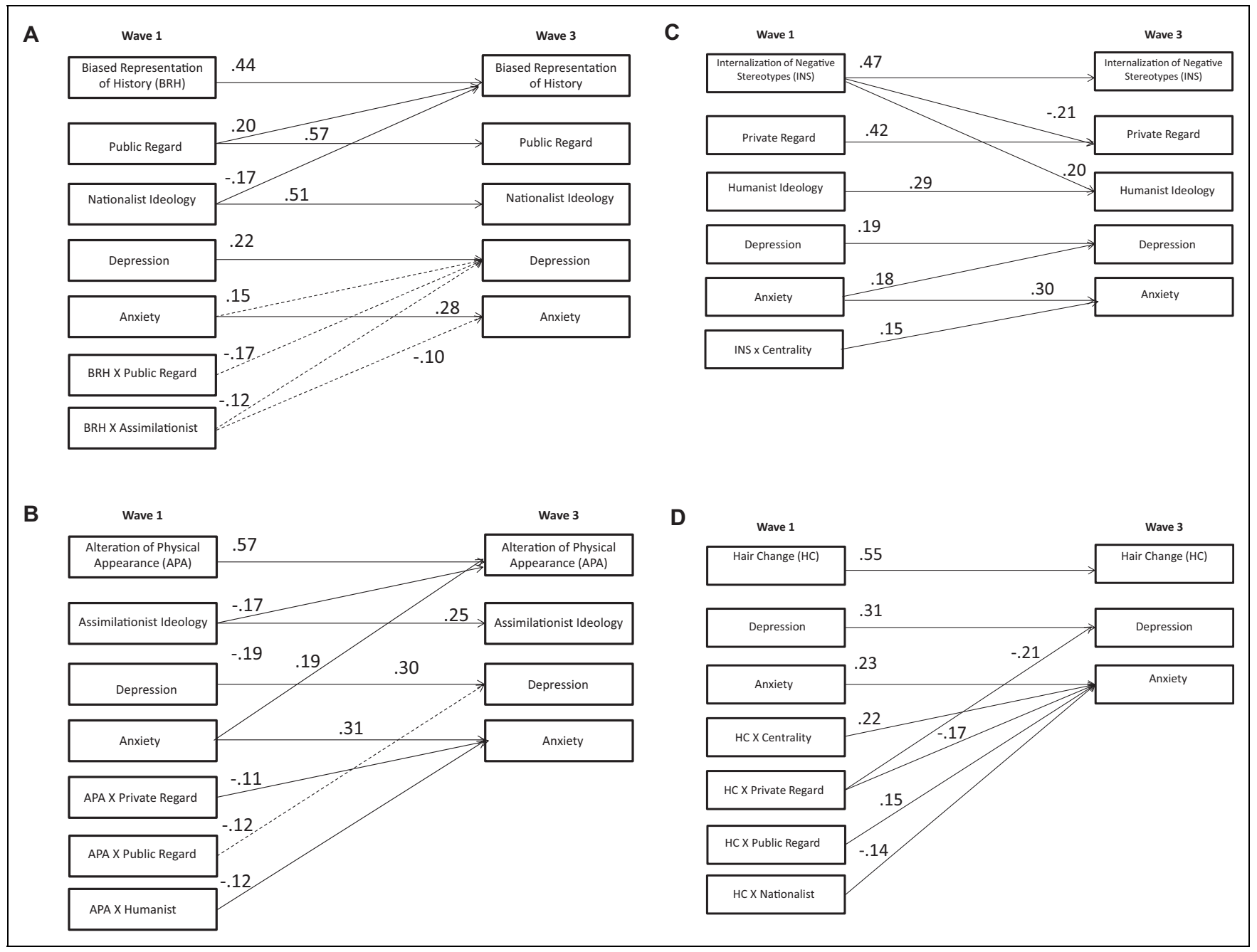

Figure I. Cross-lagged model examining internalized racism (BRH-biased representation of history: Panel A; APA-alteration of physical appearance: Panel B; INS-internalization of negative stereotypes: Panel C; HC-hair change: Panel D), racial identity, and psychological distress. Standardized coefficients for significant and trend-level (dotted line) paths are shown. Demographic covariates, all racial identity dimensions, and their interaction effects with WI internalized racism also were included in each model but, for simplicity, only significant coefficients for effects involving internalized racism subscales and significant interaction effects are presented. Output summarizing demographic and additional racial identity cross-lagged effects, model intercorrelations, and other nonsignificant coefficients are included in the Supplemental Material.

moderate $(b=-.08, p=.20)$ levels of private regard (Figure 2D). Among individuals who strongly endorsed hair change internalized racism beliefs, those with the highest levels of private regard exhibited the lowest levels of depression distress in the sample.

Anxiety. As with depression distress, hair change beliefs at W1 did not predict anxiety distress at W3 $(\beta=-0.07, S E=0.04$, $p=.23)$. However, the hair change $\mathrm{x}$ centrality $(\beta=0.22$, $S E=0.04, p=.00)$, hair change $\mathrm{x}$ private regard $(\beta=-0.17$, $S E=0.04, p=.01)$, the hair change $\mathrm{x}$ public regard $(\beta=$ $0.15, S E=0.04, p=.02$ ), and the hair change $\mathrm{x}$ nationalist $(\beta=-0.14, S E=0.05, p=.03)$ interactions were significant.

Simple slope analyses revealed that hair change beliefs were negatively associated with anxiety distress at low levels of racial centrality $(b=-.18, p=.00)$, but unrelated to anxiety distress at moderate $(b=-.05, p=.23)$ and high levels of centrality ( $b=.08, p=.19$; Figure 2E). Hair change beliefs were negatively associated with anxiety distress at high levels of private regard $(b=-.16, p=.01)$, but unrelated to anxiety distress at low $(b=.06, p=.33)$ and moderate $(b=-.05, p=.23)$ levels of private regard (Figure 2F). Hair change beliefs were negatively associated with anxiety distress at low levels of public regard $(b=-.15, p=.01)$, but unrelated to anxiety distress at moderate $(b=-.05, p=.23)$ and high $(b=.05, p=.45)$ levels of public regard (Figure 2G). Finally, hair change beliefs were associated with decreases in anxiety distress at high $(b=-.15, p=.02)$, but not low $(b=.06, p=.38)$ and moderate $(b=-.05, p=.23)$ levels of nationalist ideology (Figure 2H). Among individuals who endorsed the highest levels of hair change beliefs, it was those with modest endorsement of racial centrality, low public regard, and high levels 
of private regard and nationalist ideology who experienced the lowest levels of anxiety distress. The two-way interactions predicting W3 anxiety distress were not significant for hair change beliefs and assimilationist, humanist or minority ideology.

\section{Discussion}

The aim of this study was to increase understanding of the associations between internalized racism, racial identity, and psychological distress. Although bivariate correlations suggested that internalized racism beliefs at W1 were associated with anxiety and depressive symptoms at $\mathrm{W} 3$, the general pattern of results did not suggest a link between internalized racism and increased psychological distress after taking into account sociodemographic factors, prior racial discrimination experiences and past psychological distress. Yet, the results also suggested that, in some cases, the impact of internalized racism on subsequent psychological distress is influenced by African American young adults' beliefs about the significance and meaning of race.

\section{Belief in a Biased Representation of History}

In contrast to prior studies which focus on internalized racism as a composite construct, a strength of the current study was the examination of specific internalized racism beliefs. Biased representation of history beliefs such as "Cannibalism was widely practiced in Africa" and "There were no institutions of higher learning in Africa" were not generally associated with later psychological distress in the context of racial identity beliefs. One possible explanation is the low levels and variation of biased representation of history beliefs in the sample; yet several biased representation of history racial identity interactions approached significance. For example, low public regard $(p=.08)$ and low levels of assimilationist ideology $(p=.05)$, coupled with the endorsement of biased representation of history beliefs, conferred greater levels of subsequent psychological distress. Though we proceed with caution, these data suggest the possibility that beliefs that others do not see Blacks favorably and low endorsement of beliefs emphasizing similarities between Blacks and White American society, coupled with false historical beliefs about African people, confer increased psychological distress. Evaluation of these trends will require careful evaluation in a larger sample of African American young adults.

\section{Alteration of Physical Appearance}

Alteration of physical appearance beliefs were unrelated to depression distress, but high levels of private regard and humanist ideology, coupled with the endorsement of alteration of physical appearance beliefs were consistent with a protectiveenhancing (Luthar et al., 2000) pattern of protection, whereby individuals engage with stress (i.e., alteration of physical appearance beliefs) such that their competence is improved with increasing risk. Higher levels of alteration of physical appearance attitudes at Time 1 were associated with decreased anxiety symptoms at Time 2, but only for those who felt positively about being Black and who emphasized the commonalities between all people regardless of their racial and/or ethnic background (i.e., high private regard and humanist ideology, respectively). Numerous studies have noted the protective effects of high levels of private regard against other forms of race-related stress (Sellers \& Shelton, 2003; Sellers et al., 2006), and our study suggests that these racial identity beliefs may also protect against the effects of alteration of physical appearance internalized racism beliefs. It could be that private regard beliefs provide African American young adults with tools (e.g., increased self-concept; Neblett et al., 2012) to counteract and neutralize alteration of physical appearance beliefs, enhancing psychological wellbeing over time. With regard to humanist ideology, prior research suggests that a de-emphasis on race may have deleterious psychological consequences for African Americans (i.e., Parham \& Helms, 1985a, 1985b) and may lead to negative self-perceptions (Crocker \& Major, 1989). Our results, however, suggest that humanist ideology, in and of itself, does not confer negative psychological well-being. In fact, it may be that if one views the Black experience in terms being an individual, and not through a racial lens, they experience less overall distress even when having thoughts about altering physical features often associated with race.

\section{Internalization of Negative Stereotypes}

The model examining internalization of negative stereotypes beliefs was the only one to reveal a statistically significant link between internalized racism and increased subsequent psychological distress, after taking into account racial identity. Those who felt being Black was a central aspect of their identity, who also endorsed negative stereotypical beliefs about Black people experienced greater anxiety distress over time. This result is consistent with recent research linking internalization of negative stereotypes internalized racism beliefs with psychological distress, particularly in the context of racial discrimination (i.e., Graham et al., 2016; Molina \& James, 2016; Mouzon \& McLean, 2017; Sosoo et al., 2019). It is not surprising that endorsing negative stereotypes about Blacks, when being Black is a central and important aspect of one's identity, might cause increased dissonance and distress.

\section{Hair Change}

Several significant interactions emerged in the hair change model, and this model was the only one to contain a significant result for depressive symptom distress. Private regard exhibited a protective-enhancing pattern of resilience, such that higher levels of hair change beliefs at W1 were associated with less distress from depressive symptoms at W3, but only for those with high levels of private regard beliefs. Thus, even if individuals possessed or endorsed high levels of cognitions such as "It is okay to straighten or relax my hair" and "Straight hair is better than my natural hair texture" at W1, feeling positively about being Black protected against these beliefs and led to fewer depressive symptoms and enhanced psychological well-being over time. As suggested above, positive beliefs about being 


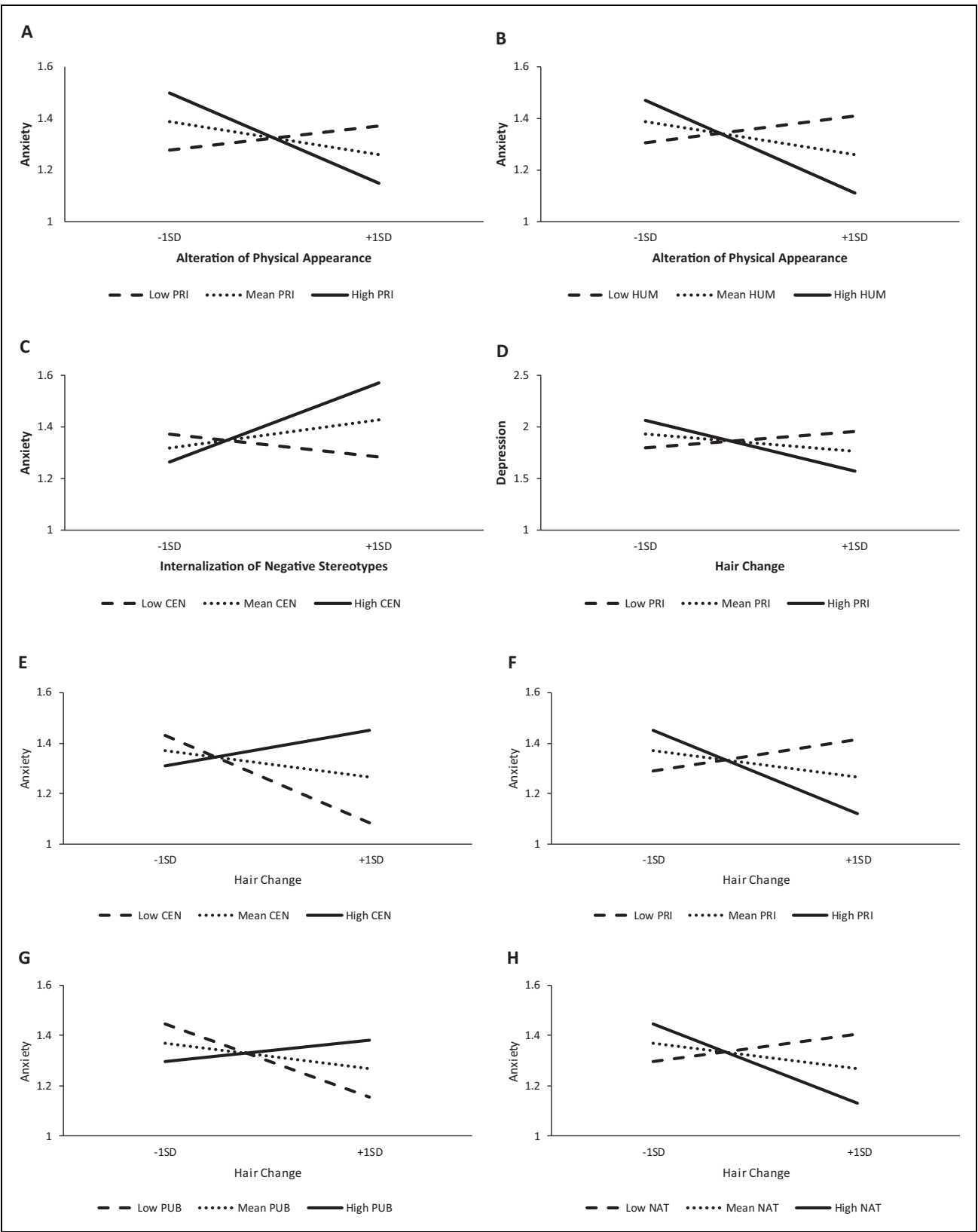

Figure 2. Interactions between Wave I Alteration of Physical Appearance: (panels A-B); Internalization of Negative Stereotypes (panel C); Hair Change: (panels D-H) and W3 psychological distress at low (-ISD), mean, and high (+ISD) levels of racial identity. Note. PRI = Private Regard; HUM = Humanist Ideology; CEN = Centrality; PUB = Public Regard; NAT = Nationalist Ideology.

African American (i.e., high private regard) may mitigate and override negative societal messages about wearing one's hair naturally (possibly by enhancing self-concept), counteract the negative impact of these beliefs on one's psyche (Harrell, 1999), and decrease psychological distress over time.

Low racial centrality, high private regard, low public regard and high nationalist ideology all combined with hair change internalized racism beliefs to enhance psychological wellbeing (i.e., decreased anxiety distress). The latter three are consistent with prior studies demonstrating protective effects of racial identity in the context of racial discrimination (e.g., Sellers \& Shelton,
2003). Indeed, our results suggest that these racial identity beliefs trump and protect against some of the negative psychological effects that could result from negative views about one's hair.

While racial centrality is found to be protective in many studies of discrimination, our study suggests a more favorable psychological profile for African American young adults with modest racial centrality. Though counterintuitive, it makes sense that individuals who are less likely to see race as a defining personal characteristic, may experience less anxiety over time when endorsing cognitions consistent with negative feelings about a physical feature associated with race - in this case, 
hair. As suggested previously with humanist ideology and biased representation of history beliefs, our findings support the idea that there are not good or bad racial identity beliefs, but what matters is how the beliefs combine with other race-related beliefs to influence well-being over time.

\section{Limitations and Future Directions}

The current study is one of the first to explore the longitudinal associations between internalized racism beliefs and psychological distress, while both controlling for experiences of racial discrimination and exploring the moderating influence of racial identity beliefs. Although there are several strengths associated with the present work, future research should address some limitations of our study. First, we are limited in generalizability since our sample was drawn from a single geographic location and predominantly female. Second, some of the subscales in the internalized racism measure had low reliability scores. Reliabilities for some racial identity scales also were modest, probably due to the small number of scale items, and may have compromised the ability to detect racial identity effects. Third, conceptual similarities and differences between internalized racism and racial identity remain an unresolved question. Bailey et al. (2011) suggested that internalized racism is a negative component of Black racial identity; yet, our data, which reveals small to moderate correlations between internalized racism and racial identity, and recent work by Fuller-Rowell et al. (2020) do not support the idea that the two are identical. Future research should seek to clarify how internalized racism is distinct from racial identity.

Our study suggests several additional leads for future research. First, the results suggest that individuals can both endorse high levels of maladaptive internalized racism beliefs in the context of specific racial identity beliefs, but still report lower levels of psychological distress over time. Molina and James (2016) suggested that since negative stereotypes about African Americans are common in U.S. society, holding internalized racism beliefs may not affect individuals acutely. Additionally, in some cases, racial identity beliefs that have been found to protect against race-related stress (e.g., racial centrality), may confer vulnerability in the context of internalized racism beliefs. Future research should examine not only internalized racism, but other combinations of cultural beliefs and processes that may play a role in how internalized racism impacts distress. For instance, constructs such as racial socialization messages (parental messages about the significance and meaning of race; Hughes et al., 2006) or critical consciousness (the process by which marginalized groups critically evaluate and challenge societal oppression; Diemer et al., 2016; Freire, 2000) may also account for how internalized racism impacts psychological health in the context of specific racial identity beliefs. In other words, while this study specifically examines racial identity beliefs, there are many other race-related processes and constructs that likely shape the context of internalized racism messages. Future studies should explore how a confluence of race-related processes may shield from and increase vulnerability to the pernicious effects of internalized racism beliefs over time.

Second, though it was not a focus of the current study, the results revealed a number of associations worth examination in future studies. Several W1 covariates such as age, gender, maternal educational attainment, prior discrimination experiences and initial levels of psychological distress were related to internalized racism beliefs over time. For example, increased age was associated with decreased internalization of negative stereotypes and hair change beliefs, and women were more likely to experience decreases in alteration of physical appearance beliefs and increases in internalization of negative stereotypes beliefs at W3 relative to men, suggesting relations between age, gender, and changes in internalized racism beliefs. Links between maternal educational attainment and decreased biased representation of history beliefs and between prior discrimination experiences and decreased endorsement of alteration of physical appearance beliefs also lay the foundation to consider factors that shape internalized racism beliefs over time. There were also bidirectional associations between racial identity and internalized racism. For instance, higher levels of public regard at W1 were associated with higher levels of biased representation of history beliefs at W3, while initial levels of nationalist and assimilationist ideology were negatively associated with biased representation of history and alteration of physical appearance beliefs, respectively, at W3. In the reverse direction (internalized racism $\rightarrow$ racial identity), higher levels of internalization of negative stereotypes at W1 were associated with lower levels of private regard at W3. Just as other longitudinal studies highlight how racial identity beliefs change over time during young adulthood (Willis \& Neblett, 2019), these changes may also be occurring among internalized racism beliefs. Future studies should explore how sociodemographic factors, prior experiences, and psychological functioning shape the development of internalized racism, as well as how internalized racism and racial identity beliefs change together over time to influence the psychological well-being of African American youth.

\section{Conclusion}

Additional studies are needed to better understand the effects of internalized racism on mental health outcomes (Williams \& Mohammed, 2009). In contrast to prior research examining internalized racism, we did not find overwhelming evidence in this study that internalized racism is linked with changes in psychological distress. Yet, our results also suggest that racial identity beliefs can interact with internalized racism beliefs to shape subsequent psychological well-being in ways that are both consistent and inconsistent with prior research examining racial identity in the context of other race-related stressors. Some racial identity beliefs -most consistently private regard- counteract and mitigate internalized racism beliefs, while others may exacerbate negative psychological distress, particularly when racial identity and internalized racism beliefs are misaligned or individuals grapple with negative beliefs about their identity. Thus, exploring both 
internalized racism and racial identity beliefs in combination, as well as the factors that shape the development of and changes in internalized racism, are vital to understanding the trajectories of psychological well-being among African American youth (Hughes et al., 2015). In light of omnipresent societal messages that suggest the inferiority of Black people, it is critical to further examine what cultural assets Black young adults can apply to promote a positive self-concept that reflects both acceptance of and pride about one's own racial and/or ethnic identity and to promote positive mental health.

\section{Author Contributions}

Henry A. Willis has contributed to conception, design, analysis, and interpretation; drafted the manuscript; critically revised the manuscript; gave the final approval; and agreed to be accountable for all aspects of work ensuring integrity and accuracy. Effua E. Sosoo and Donte L. Bernard have contributed to conception, design, and interpretation; drafted the manuscript; critically revised the manuscript; gave the final approval; and agreed to be accountable for all aspects of work ensuring integrity and accuracy. Aaron Neal has contributed to conception, and interpretation; drafted the manuscript; critically revised the manuscript; gave the final approval; and agreed to be accountable for all aspects of work ensuring integrity and accuracy. Enrique W. Neblett has contributed to conception, design, acquisition, analysis, and interpretation; drafted the manuscript; critically revised the manuscript; gave the final approval; and agreed to be accountable for all aspects of work ensuring integrity and accuracy.

\section{Declaration of Conflicting Interests}

The author(s) declared no potential conflicts of interest with respect to the research, authorship, and/or publication of this article.

\section{Funding}

The author(s) disclosed receipt of the following financial support for the research, authorship, and/or publication of this article: This study was supported by the National Institute of Mental Health (T32 MH18869, PIs: Danielson \& Kilpatrick).

\section{Open Practices}

The raw data, analysis code, and materials used in this study are not openly available but are available upon request to the corresponding author. No aspects of the study were pre-registered. Data and materials for this study have not been made publicly available. The design and analysis plans were not preregistered.

\section{ORCID iD}

Henry A. Willis (D) https://orcid.org/0000-0002-7427-0340

\section{Supplemental Material}

The supplemental material for this article is available online.

\section{References}

Arnett, J. J. (2003). Conceptions of the transition to adulthood among emerging adults in American ethnic groups. New Directions for Child and Adolescent Development, 2003(100), 63-76.

Babajide, A., Ortin, A., Wei, C., Mufson, L., \& Duarte, C. S. (2020). Transition cliffs for young adults with anxiety and depression: Is integrated mental health care a solution? The Journal of Behavioral Health Services \& Research, 47, 275-292.

Bailey, T.-K. M., Chung, Y. B., Williams, W. S., Singh, A. A., \& Terrell, H. K. (2011). Development and validation of the internalized racial oppression scale for black individuals. Journal of Counseling Psychology, 58(4), 481-493. https://doi.org/10.103 7/a0023585

Banks, K. H., \& Kohn-Wood, L. P. (2007). The influence of racial identity profiles on the relationship between racial discrimination and depressive symptoms. Journal of Black Psychology, 33(3), 331-354. https://doi.org//10.1177/0095798407302540

Bernard, D. L., Hoggard, L. S., \& Neblett, E. W. (2018). Racial discrimination, racial identity, and impostor phenomenon: A profile approach. Cultural Diversity \& Ethnic Minority Psychology, 24(1), 51-61. https://doi.org/10.1037/cdp0000161

Brown, D. L., \& Segrist, D. (2016). African American career aspirations examining the relative influence of internalized racism. Journal of Career Development, 43(2), 177-189. https://doi.org/10. 1177/0894845315586256

Bynum, M. S., Best, C., Barnes, S. L., \& Burton, E. T. (2008). Private regard, identity protection and perceived racism among African American males. Journal of African American Studies, 12(2), 142-155.

Carter, R. T. (2007). Racism and psychological and emotional injury: Recognizing and assessing race-based traumatic stress. The Counseling Psychologist, 35(1), 13-105. https://doi.org/10.1177/ 0011000006292033

Castle, K., Conner, K., Kaukeinen, K., \& Tu, X. (2011). Perceived racism, discrimination, and acculturation in suicidal ideation and suicide attempts among black young adults. Suicide and LifeThreatening Behavior, 41(3), 342-351.

Clark, R., Anderson, N. B., Clark, V. R., \& Williams, D. R. (1999). Racism as a stressor for African Americans. A biopsychosocial model. The American Psychologist, 54(10), 805-816. https:// doi.org/10.1037/0003-066X.54.10.805

Clarke, J. H. (1991). Notes for an African world revolution: Africans at the crossroads. African World Press.

Cokley, K. O. (2002). Testing cross's revised racial identity model: An examination of the relationship between racial identity and internalized racialism. Journal of Counseling Psychology, 49(4), 476-483. https://doi.org/10.1037/0022-0167.49.4.476

Crocker, J., \& Major, B. (1989). Social stigma and self-esteem: The selfprotective properties of stigma. Psychological Review, 96(4), 608-630.

David, E. J. R., Schroeder, T. M., \& Fernandez, J. (2019). Internalized racism: A systematic review of the psychological literature on racism's most insidious consequence. Journal of Social Issues, 75(4), 1057-1086. https://doi.org/10.1111/josi.12350

Derogatis, L. R. (1996). SCL-90-R: Symptom Checklist-90-R: administration, scoring, and procedures manual. NCS Pearson.

Derogatis, L. R., \& Unger, R. (2010). Symptom checklist-90-revised. Corsini Encyclopedia of Psychology. https://doi.org/10.1002/ 9780470479216.corpsy0970

Diemer, M. A., Rapa, L. J., Voight, A. M., \& McWhirter, E. H. (2016). Critical consciousness: A developmental approach to addressing marginalization and oppression. Child Development Perspectives, 10(4), 216-221. 
Doherty, E. E., Green, K. M., Reisinger, H. S., \& Ensminger, M. E. (2008). Long-term patterns of drug use among an urban AfricanAmerican cohort: The role of gender and family. Journal of Urban Health, 85(2), 250-267.

Freire, P. (2000). Pedagogy of the oppressed (30th anniversary ed.). Continuum.

Fuller-Rowell, T. E., Nichols, O. I., Burrow, A. L., Ong, A. D., Chae, D. H., \& El-Sheikh, M. (2020). Day-to-day fluctuations in experiences of discrimination: Associations with sleep and the moderating role of internalized racism among African American college students. Cultural Diversity and Ethnic Minority Psychology. https://doi.org/10.1037/cdp0000342

Gil, A. G., Vega, W. A., \& Turner, R. J. (2002). Early and midadolescence risk factors for later substance abuse by African Americans and European Americans. Public Health Reports, 117, S15-29.

Graham, J. R., Sorenson, S., \& Hayes-Skelton, S. A. (2013). Enhancing the cultural sensitivity of cognitive behavioral interventions for anxiety in diverse populations. The Behavior Therapist, 36(5), 101.

Graham, J. R., West, L. M., Martinez, J., \& Roemer, L. (2016). The mediating role of internalized racism in the relationship between racist experiences and anxiety symptoms in a Black American sample. Cultural Diversity and Ethnic Minority Psychology, 22(3), 369-376. https://doi.org/10.1037/cdp0000073

Harrell, C. J. P. (1999). Manichean psychology: Racism and the minds of people of African descent. Howard University Press.

Harrell, S. P. (1994). The racism and life experience scales. Unpublished manuscript.

Horowitz, L. M., Rosenberg, S. E., Baer, B. A., Ureño, G., \& Villaseñor, V. S. (1988). Inventory of interpersonal problems: psychometric properties and clinical applications. Journal of Consulting and Clinical Psychology, 56(6), 885.

Hughes, D., Rodriguez, J., Smith, E. P., Johnson, D. J., Stevenson, H. C., \& Spicer, P. (2006). Parents' ethnic-racial socialization practices: A review of research and directions for future study. Developmental psychology, 42(5), 747.

Hughes, M., Kiecolt, K. J., Keith, V. M., \& Demo, D. H. (2015). Racial identity and well-being among African Americans. Social Psychology Quarterly, 78(1), 25-48. https://doi.org/10.1177/ 0190272514554043

Hurd, N. M., Varner, F. A., Caldwell, C. H., \& Zimmerman, M. A. (2014). Does perceived racial discrimination predict changes in psychological distress and substance use over time? An examination among Black emerging adults. Developmental Psychology, $50(7), 1910$.

Jones, C. P. (2000). Levels of racism: A theoretic framework and a gardener's tale. American Journal of Public Health, 90(8), 1212-1215. https://doi.org/10.2105/AJPH.90.8.1212

Lee, D. B., Gaskin, A. L., Jones, S. C. T., Harrell, S. P., Banks, K. H., Kohn-Wood, L., Sellers, R. M., \& Neblett, E. W. Jr. (2020). The Daily Life Experiences Scale. Factor structure, reliability, validity, and measurement invariance for African American males and females. Measurement and Evaluation in Counseling and Development, 1-14. https://doi.org/10.1080/07481756.2020.1827436

Luthar, S. S., Cicchetti, D., \& Becker, B. (2000). The construct of resilience: A critical evaluation and guidelines for future work. Child Development, 71(3), 543-562.
Martin, P. P., Wout, D., Nguyen, H., Sellers, R. M., \& Gonzalez, R. (2010). Investigating the psychometric properties of the multidimensional inventory of Black identity in two samples: The development of the MIBI-S [Unpublished manuscript].

Molina, K. M., \& James, D. (2016). Discrimination, internalized racism, and depression: A comparative study of African American and AfroCaribbean adults in the US. Group Processes \& Intergroup Relations, 19(4), 439-461. https://doi.org/10.1177/1368430216641304

Mouzon, D. M., \& McLean, J. S. (2017). Internalized racism and mental health among African-Americans, US-born Caribbean Blacks, and foreign-born Caribbean Blacks. Ethnicity \& Health, 22(1), $36-48$.

Neblett, E. W., \& Carter, S. E. (2012). The protective role of racial identity and Africentric worldview in the association between racial discrimination and blood pressure. Psychosomatic Medicine, 74(5), 509-516. https://doi.org/10.1097/PSY.0b013e3182583a50

Neblett, E. W., Rivas-Drake, D., \& Umaña-Taylor, A. J. (2012). The promise of racial and ethnic protective factors in promoting ethnic minority youth development. Child Development Perspectives, 6(3), 295-303. https://doi.org/10.1111/j.1750-8606.2012.00239.x

Parmer, T. A., Arnold, N., Natt, H. R., \& Janson, L. (2004). Physical attractiveness as a process of internalized oppression and multigenerational transmission in African American families. The Family Journal: Counseling and Therapy for Couples and Families, 12, 230-242.

Parham, T. A., \& Helms, J. E. (1985a). Attitudes of racial identity and self-esteem of Black students: An exploratory investigation. Journal of College Student Personnel, 26, 143-147.

Parham, T. A., \& Helms, J. E. (1985b). Relation of racial identity attitudes to self-actualization and affective states of Black students. Journal of Counseling Psychology, 32(3), 431-440.

Perry, T., Steele, C., \& Hilliard, A. G. (2003). Young, gifted, and Black: Promoting high achievement among African-American students. Beacon Press.

Peveler, R. C., \& Fairburn, C. G. (1990). Measurement of neurotic symptoms by self-report questionnaire: Validity of the SCL-90 R. Psychological Medicine, 20(4), 873-879.

Priest, N., Paradies, Y., Trenerry, B., Truong, M., Karlsen, S., \& Kelly, Y. (2013). A Systematic review of studies examining the relationship between reported racism and health and wellbeing for children and young people. Social Science \& Medicine, 95, 115-127. https://doi.org/10.1016/j.socscimed.2012.11.031

Seaton, E. K. (2009). Perceived racial discrimination and racial identity profiles among African American adolescents. Cultural Diversity \& Ethnic Minority Psychology, 15(2), 137-144. https://doi.o $\mathrm{rg} / 10.1037 / \mathrm{a} 0015506$

Sellers, R. M., Copeland-Linder, N., Martin, P. P., \& Lewis, L. R. (2006). Racial identity matters: The relationship between racial discrimination and psychological functioning in African American adolescents. Journal of Research on Adolescence, 16(2), 187-216. https://doi.org/10.1111/j.1532-7795.2006.00128.x

Sellers, R. M., Rowley, S. A. J., Chavous, T. M., Shelton, J. N., \& Smith, M. A. (1997). Multidimensional model of racial identity: A reconceptualization of African American racial identity. Personality and Social Psychology Review, 2(1), 18-39. https://doi.org/ $10.1207 / \mathrm{s} 15327957 \mathrm{pspr} 0201$ 
Sellers, R. M., \& Shelton, J. N. (2003). The role of racial identity in perceived racial discrimination. Journal of Personality and Social Psychology, 84(5), 1079-1092. https://doi.org/10.1037/0022-3 514.84.5.1079

Smedley, B. D., Myers, H. F., \& Harrell, S. P. (1993). Minority-status stresses and the college adjustment of ethnic minority freshmen. The Journal of Higher Education, 64(4), 434-452.

Smith, T. B., \& Silva, L. (2011). Ethnic identity and personal well-being of people of color: A meta-analysis. Journal of Counseling Psychology, 58(1), 42. https://doi.org/10.1037/a 0021528

Sosoo, E. E., Bernard, D. L., \& Neblett, E. W. (2019). The Influence of internalized racism on the relationship between discrimination and anxiety. Cultural Diversity \& Ethnic Minority Psychology, 26(4), 570-580.

Speight, S. L. (2007). Internalized racism: One more piece of the puzzle. The Counseling Psychologist, 35(1), 126-134. https://doi.org/ 10.1177/0011000006295119

Sue, D. W. (Ed.). (2010). Microaggressions and marginality: Manifestation, dynamics, and impact. John Wiley \& Sons.

Taylor, J. (1990). Relationship between internalized racism and marital satisfaction. Journal of Black Psychology, 16(2), 45-53.

Taylor, J., Henderson, D., \& Jackson, B. B. (1991). A holistic model for understanding and predicting depressive symptoms in African American women. Journal of Community Psychology, 19(4), 306-320. https://doi.org/10.1002/1520-6629(199110)19:4<306:: AID-JCOP2290190403>3.0.CO;2-Z

Tull, S. E., Wickramasuriya, T., Taylor, J., Smith-Burns, V., Brown, M., Champagnie, G., Daye, K., Donaldson, K., Solomon, N., Walker, S., Fraser, H., \& Jordan, O. W. (1999). Relationship of internalized racism to abdominal obesity and blood pressure in Afro-Caribbean women. Journal of the National Medical Association, 91(8), 447-452.

Williams, D. R., \& Chung, A. M. (1999). Racism and health. In R. Gibson \& J. S. Jackson (Eds.), Health in Black America. SAGE.

Williams, D. R., \& Mohammed, S. A. (2009). Discrimination and racial disparities in health: Evidence and needed research. Journal of Behavioral Medicine, 32(1), 20-47. https://doi.org/10.1007/ s10865-008-9185-0

Willis, H. A, \& Neblett, E. W. (2019). Racial identity and changes in psychological distress using the multidimensional model of racial identity. Cultural Diversity and Ethnic Minority Psychology. https://doi.org/10.1037/cdp0000314

\section{Author Biographies}

Henry A. Willis is a clinical psychology doctoral candidate at the University of North Carolina at Chapel Hill. His research focuses on exploring the relationship between online and offline racial discrimination and mental health outcomes, understanding sociocultural protective factors and how they impact psychopathology within African Americans, creating cultural adaptations of evidence-based treatments, and utilizing mobile-health technology to increase access to mental health treatments for underserved populations.

Effua E. Sosoo is a clinical psychology doctoral candidate at the University of North Carolina at Chapel Hill. Her research focuses on the physiological and psychological impacts of racial discrimination on Black individuals. Her clinical interests focus on serving and empowering Black and/or incarcerated populations.

Donte L. Bernard is a T32 postdoctoral fellow at Medical University of South Carolina. His research focuses on examining the psychological and behavioral health consequences of racial discrimination and traumatic stress, with specific emphasis placed on understanding how culturally relevant moderators and mechanisms may hinder or exacerbate this relationship.

Aaron Neal is a clinical psychology graduate student at the University of Michigan. His research is situated within the fields of clinical and developmental psychology and focuses on the use of community-based participatory research to understand how institutional racism impacts the health, well-being, and development of Black youth.

Enrique W. Neblett is a professor of Health Behavior and Health Education at the University of Michigan School of Public Health and associate director of the Detroit CommunityAcademic Urban Research Center. His research focuses on understanding how racism-related stress influences the mental and physical health of African American young people. 